\title{
DE DUKAAT EN DE STANDPRIJS VOOR GOUD IN NEDERLAND.
}

\author{
(Ingezonden.)
}

Wanneer de handelaar in edele metalen in zïn operatiën den voor goud bestaanden standprijs van $f 1442.60$ gebruikt, dan' vermoedt hij waarschijnlijk niet, dat dit getal een erfatuk zijner voorvaderen is, waarvan de oorsprong tot aan het midden van de 17e eeuw opklimt, dan zict bij stellig niet het minste verband tusschen dien prijs en den koers eener munt, die wel op de voornaamste plaatsen der wereld als negotiepenning een prij belangrijke rol nog speelt, maar als standpenning in Europa reeds lang heeft uitgediend.

Gaat men de specielijsten van vorige eeuwen $n a$, dan is het inderdaad rerwonderlijk op te merken, hoe weinig munten haar bestaan tot den tegenwoordigen tijd hebben kunnen rekken. Waar vindt men, om bij ons land te blijven en niet te spreken van de tallooze zilveren munten, die er vroeger in onloop waren, waar vindt men den Filips lrinixerd, den grooten Reaal, den St. Andries-gulden, den Rosenobel, den Rijder en tal van andere gouden munten, die allen in de verschillende provinciën angemunt en in circulatie gebracht werden? Haar spoor zou alléén nog to vinden zijn in oude oorkonden, indien enkelen niet het geluk gehad badjen in het penningkabinet van een verzamelaar een' schuilplaate te vinden tegen het vandalisme van den nieuweren tijd.

Alleen de gouden Dukaal heeft zich door de eeuwen heen stande gehouden in alle omwentelingen op het gebied van bet muntwezen. Zijn stempel moge, vooral in den beginne, herbardelijk gewijzigd zijn, zijn gewicht is van de rroegste tijden af tot op den huidigen dag niet veranderd en ook het gehalte is, behoudens kleine schommelingen, stee ls standrastig gebleven. De Dukaat werd in het jaar 1140 onder Roger II van Sicilië het eerst gemurt met bet omechrift: Sit tibi, Christe, datus, quem tu regis, iste Ducalus, d. i : U, Curistus! zij dit hertogdom, dat gij regeert, gewijd. Naar het laatste woord van dit randschrift werd het sluk Dukaat genoemd. Van Sicilië uit verspreidde de munt zich we:dra 
over geheel Italië. De pausen en de verschillende wereldlijke vorsten lieten $\mathrm{z} \theta$ in hun staten aanmunten en de voorzijde gewoonlijk met hun eigen beeltenis, de keerzijde niet zelden met die van een heilige voorzien, terwijl gewijde spreuken tot randschrift dienden. Het valt moeielijk te bepalen, of al deze stukken volkomen nauwkeurig hetzelfde gewicht en gebalte hadden, maar er bestaan gegronde redenen om dit aan te nemen, daar in de oude plakkaten en ordonnantiën de waarde van alle Italiaassche Dukaten, zonder onderscheid van stempel, gelijk gesteld werd. Zoo wordt het gewicht van de "Dukaten van Italien, Romen ende Venegien" in een ordonnantie van Karel $V$, van het jaar 1548, bepaald op "twe ingelschen ende seren azen stijf" (*) terwijl zoowel blijkens deze als alle voorzaande en volgende ordonnantiën geen verschil in den koers bestond.

De middeleeuwen waren, met haar kruistochten naar het Heilige Land, voor Italië bet tijdperk van de grootste krachtsontwikkeling op het gebied van den handel. De wissel rond hier, door het sterk toenemend verkeer met andere natiën, zijn oorsprong; het dubbel boekhouden werd or het eerst in practijk gebracht en menige uitdrukking in de boeken onzer kooplieden wijst het vaderland van de dubbele methode aan, getuige om een enkel voorbeeld te noemen, Conto-mio, dat nog beden ten dage voor de Mijne-rekening in gebruik is. Het is dus niet te verwonderen, dat de regeeringen van de rerschillende volkeren, die met Italië handel dreven, middelen beraamden om het bandelsverkeer gemakkelijk te maken, en dat zij, wet het oog op den in Italië gangbaren Dukaat, munten van hetzelfde gewicht en gehalte lieten vervaardigen. Spanje en Portugal gingen hierin voor, Hongarije en andere landen volgden. Van al deze Dukaten gingen volgens de oudste ordonnantiën en plakkaten gemiddeld "LXX in 't mare fiju goudt", zoodat het gewicht van één stuk was „II ingelschen IX azen stijf”, dats twe penninghen XVIII ghreynen schaers", en hoowel de uitdrukking "fijn goudt" niet de beteekenis had, die men tegenwoordig daaraan geeft $(t)$, kan toch, met het oog op het doel der aanmunting

(*) Van de vroegste tijden af, werd in ons land het Mark T'rooisch als gouden zilvergewicht gebruikt. Fen Mark had 8 ons à 20 Eugels à 32 Azen eu was gelijk aan 246,084 Gram.

$(\dagger)$ "Fijn goudt " beteekende oorspronkelijk goud van het hoogste gehalte, dat door de destijds gebrekkige wetenschappelijke behandeling verkregen kon worden. Later werd die beteekenis eenigszins gewijzigd en noemde men het muntgoud voor standpenningen "fijn goudt." 
en het geringe rerschil in koers, angenomen worden, dat bet wettelijk gehalte gelijł was aan dat ran den Italiaanschen Dukaat.

Dit het bovenstaande blijkt, dat de oorspronkelijke Dukart 2 azen lichter was dan de overigen. Dit rerschil moet, althans voor een gedeelte, toegeschreven worden an slijtage. Het is bekend, dat het gewichtsverlies docr wrijving grooter wordt, naarmate het gebalte der munt fijner is. Daar nu dukatengoud niet reel meer dan $13_{00}^{\circ}$ verschilde met fijn goud, moet het wrijvingsverlies ongeveer een maximum geweest $z$ ijn $n$, en de oude Dukaat van Italie moest dus bij rechtstreeksche weging lichter bevonden worden dan de nieuwere stukken.

Toen Maximiliaan „par la grace de Dicu, Roy des Romains tousiours Auguste", roor zijn minderjarigen zoon Philips den Schoone, aartshertog ran Oostenrijk, bet bewind over Nederland in handen had, werden hier de Italiaansche en Hongaarsche Dulraten ganghaar. De eersten hadden volyeus de ordonnantie van 14 December 1489 koers voor "quatre souls, deux deniers gros", de laatsten voor "qualre sols, quatre deniers" (*). Het versehil in waarde was dus "twee deniers gros" of 15 cent in onze hedendaagsche munt. $\mathrm{Na}$ het huwelijk van Philips met Johanna van Arragon, dochter van "Ferdinand van Hispanië on van Elizabet" kwam ons land in nauwe betrukking tot Spanje te staan. Daardoor werden de Spaansebe Dukaten, die tot hiertoe niet in de valvatielijsten voorkwamen, na 1496 in ons land gangbaar. $Z_{i j}$ stonden in waarde gelijk aan de Hongaarsche Dukaton en bleven met deze nog geruimen tijd in omloop ${ }_{2}$ nada: bij de ordonnantie van de Staten-Generaal der Vereenigde Nederlanden van $21 \mathrm{Juli} 1622$ de Italiaansche Dukaat buiten koers gesteld werd.

Intusschen was men ook in ons land begonnen Dukaten to doen aanmunten. Volgens van Alkemade in zijn beschrijving van „de goude en zilvere gangbare penningen der graaven en graavinnen van Holland" liet graaf Willem $\nabla$, uit het Beiersche huis, die in 1377 overleed, den eeraten Dukaat vervaardigen. Hij zegt dienaangaande: "Deze penning werd genoemd Dukaat en "betéékende eigenliik de Munt van één Hertós en is de éérste

(*) Tijdens de voogdijschap van Maximiliaan en lang te poren, was ouk ten onzent als rekenmunt in gebruik de "libure" à "vingt sols" à "douze deniers" ì "24 mites de gros" of het zoogenocmde "pont Tournois." Deze munt moet in waarde gelijk gestaan hebben met het bekende Pond Vlaamsch, zooals uit het vervolg blijkt. 
"die ons ran deze soort onder de Graaveliike Munten roorkomt: "Welke naim niet on waarschiinliik vau deze Willem van Beieren "(de éérste onzer Prinsen die de naam Herlóg drueg) ziin aanvang "genomen en dezelve in deze en veele andere Landen behóuden „, heeft. Ziinde ook rólgens de getuigenis eeniger oudheids onder„zoekers, opmerkelijk, dat deze soort van Munten in gelalte en "gewigt altiid de zelve geweest en gebleoven is zó veele ééuwen "door lót nu toe, niet tegenstaande de ontelbare omkééringen "der tiiden en rólken, alsmede inzonderheid de méénigvuldige "veranderingen der Munten zóó in gehalte als gewicht bi ellk Rijk "en Landschap, ieder naar hun belang en behaagen, ingevoerd. In "welke góude Penningen bi gevólg gééue veranderlijkheid dan "alléén in de Priiz, die gesteigerd en gedaald is evenals in alle "andere Munten, oit is bespeurd geworden." En hoewel de juistheid dezer opmerking mei betrekking tot gewicht en gehalte niet betwist lan worden, verkeert de schrijver met zijn meening omtrent den oorsprong van den Dukaat.in een tegenwooraig alge-

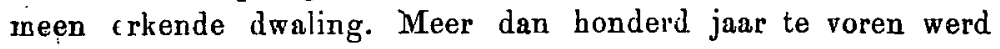
reeds in officieele stukken een andere meening uitgesproken, zooals blijkt uit een ordonnantie van 4t Augustus 1586, vegeven "door "Robbert Grave ran Leycester, Gouverneur, Capiteyn Ge"nerael der Vereenichde Nederlandtsche Provincien" waarin de volgende bepaling voorkomt:

„Ende omme te faciliteren ende accomoderen die gemeene „Koopbandel, Negotiatie ende Trafficque metlen vreraden Natien, "insonderheyt die van den H. Rijcke, Sweeden, Denemarcken, „ende Oustersche Zee Steden, ende den gemeenen Kooplieden "dozer Landen te benemen alle oorsaecke ran opdringen ende "steygeren der specien, voornementlick des Ducaets, die sij in " hare handelinge niet en mogen ontbeeren, hebben geordonneert " ende besloten, dat opte Munten sullen geslagen mogen worden "Ducaten, corresponderende in gewichte ende alloye metten op"rechten Ducaten, so jegenwoordelijck in 't Heylich Rijck gemunt "werden. Tot welcken eynde, endo opdat de selvige Koopluyden "mogen daer door gerieft ende verseeckert zijn, wij sulleo schrij"ven ende advertissement doen aen den selven van den Rijcke, "Denemarcken, Sweeden, ende Oostersche Steden, aengaende "onse Resolutie ende meeninge in desen."

In de genoemde landen was dus de oprechte Italiaansche Dukaat de meest gezochte munt voor den handel met het buitenland, en terwijl de ordonnantie geen twijfel overlaat aangaande den oor- 
sprong van dit muntstuk, geeft zij tevens do zelserheid, dat do destijds gemunte Dukaten volkomen nauwkeurig met den oorspronkelijken overeenstemden.

De Dukaat van Graaf Willem $V$, verbeeld den Prins geheel "liifs ten voet-zoolen toe in 't haruas, met blóoten hóófde, bóu"dende in de ééne hand het zwaard, in de andere het wapen"schild van Beieren; Agter, of ter ziiile, staat de Hóllandiso "lééuw; En hot omsehrift is:

„GUILL. DUX. OOMES. HOL.

„Hertóg Wirlem, Graaf vai Hólland.

„De andere ziide beeft 's Prinsen wapen-schild, gevierendééld "met de wapenen van Beieren en Holland; en rond om:

\section{"FLORINI: DE: HOLLAND: $\mathrm{z}$ : ZELAN. \\ "Gulden van Hóluand en van Zééland."}

Hoewel dit stuk geen jaartal draugt, is het toch te vermoeden, dat het vóór 1359 geslagen werd, omdat $W$ illem $V$ in dat jaar " egens krankzinnigheid werd opgesloten $\left(^{*}\right)$. Zijn broeder Albrecht. ("Aalberd") die daarop het bestuur in handen nam, liet een Dukaat vervaardigen, die van den rorigen alleen in den beeldenaar verschilt. In het begin der vijftiende eeuw werden nog door Jan van Beieren, oom van de ongeluksige Jacoba, twee verschillende Dukaten aangernunt; na dien tijd echter schijnt onder de graven van Holland deze munt niet meer vervaardigd geworden te zija. Tijdens de voogdijschap van Maximiliaan van Oostenrijk en het bestuur van zijn zoon Philips den Schoone zou trouwens de aansounting van Hollandsche Dukaten geen reden ran bestaan meer gehad hebben, omdat destijds de Hongaarsche en Spaansehe Dukaten gangbaar werden en als inlandsche munten beschouwd konden worden.

Maximiliaan bepaalde in zijn ordonnantie van 1489 , dat er Munten geopend zouden worden in Brabant, Gelderland, Vlaanderen en Holland „àfin que les pays soyent mieulx assortiz des "deniers qui se forgeront, et qui les marchans et changeurs n'ay ent "cause de porter leurs matières d'or et d'argent, hors des pays „du koy et do l'Archiduc son filz." Op dece Munten zullen zeker de Hongaarsche en later de Spaansche Dukaten, die voor bet

(*) Deze Dukaat komt voor in de verzaneling van den heer J. B. Schöne, hier ter stede. $\mathrm{H}_{i j}$ heeft een zwarte van $3,4869 \mathrm{Gram}$; zijn gehalte is naauwkeurig, voor zouver dit met den toetssteen onderzocht kon worden. Hij verschilt naar deze gegevens $I$ cent in waarde met den wichtigen Dukaat van den tegenwoordigen tijd 
verkeer in deze landen noodig waren, geslagen zijn, een meening die voorai zijn grond vindt in de kúerslijsten, die van regecringswege bij de plakkaten gevoegd werden, en waarin voortdurend gesproken wordt van: "De Ducaten van Hongarijen, Spangien "ende diegeene ghemunt in 't Rijk."

De laatstgenoemde uitdrukking kan nl. geen betrekking gehad hebben op de Italiaansche of Hollandsche Ducaten van vroegeren of lateren stempel, omdat deze in de bedoelde ralvatulijston afzonderlijk genoteerd werden. Bovendien wordt in een provisioneel plakkaat van het jaar 1594 de koers bepaald van "den dobbelen "Ducaet ende den enckelen, met twee boofden $\left(^{*}\right)$ ende 't wapen "van Spangien, in de respective geunieerde Provincien geslagen", waaruit voldoende blijkt, dat althans de Spaansche Dukaat ten onzent werd aangemunt.

Nadat de Staten-Generaal in 1581 Philips II, zoon van Keizer Karel $\nabla$, afgezworen badden, werden weder Hollandsche Dukaten vervaardigd. Een der eerste, in 1583 geslagen, beeft tot om. schrift: Vigilate, Deo Confidentes (Waakt, op God vertrouwende). Daarop volgde de "Nederlandtsche Ducaet met de Letteren." Deze heeft op de voorzijde een geharnasten man, die in de rechterhand een awaard, in de linker een bundel van zeven pijlen, het beeld der vereenigde provinciën, houdt. Het randschrift is de bekende spreuk onzer voorvaderen: Concorilia res parvae crescunt. (Eendracht maakt macht. Op de keerzijde vindt men in een vierkant: Mo-Aur. Provin. Confoe. Belg. ad. Leg. Imp. (Gouden wunt van de Vereenigde Nederlandsche provinciën). Van beide munten werden 70 stukken geslagen uit een Mark goud van 23 karaten en 8 grein ( $\dagger$ ). De ordonnantie van 2 April 1603 bepaalde daarbij, dat geen andere goudon munt vervaardigd mocht worden, en dat de remedie van gewicht $\frac{3}{4}$ Engels per Mark; die van het gebalte één grein zou mogen bedragen, terwijl het plakkaat van 21 Maart 1606 de remedie van gewicht op één Engels per Mark werks bracht. Naar de laatatgenoemde ordonnantie moesten volgens Koninklijk besluit van 19 Januari 1814 ook de toeńmalige

(*) Men had Spaansche Dukaten met de borstbeelden van Ferdinand en Isabella v. Castile, later met die van Johanua v. Arragon en haar zoon Karel V. Deze werden "Ducaten met twee hoofden" geuoemd.

$(\dagger)$ De eenheid werd vroeger, ter bepaling van het gehalte van goud, verdeeld in 24 karaten a 12 greinen; voor zilver had men de verdeeling in 12 penningen à 24 greinen. 
Dukaten worden aangemunt. En de muntwetten van 1816 en 1847 beratten werkelijk voor het gewicht en gehalte de gegevens, die uit het plakkaat ran 21 Maart 1606 voortvloeien, zooals blijkt uit de volgende berekening:

1 Mark Trooisch $=8$ ons à 20 Eng. à 32 az. $=246,084$ G. af remedie 1 Eng. $=1,538$,

Minimua-Gewicht van 70 Dukaten . . . . $\equiv 244,546 \mathrm{G}$.

244,546 G. : $70=3,494$ G. zijnde tegenwoordig het, gewicht ván den-Dulraat, volgeris do wet van 26 November 1847 .

$$
\begin{aligned}
\text { Gebalte ran den Dukat } & =23 \mathrm{kar} .8 \mathrm{gr} . \\
\text { af remedie } & =\frac{1 \%}{23 \mathrm{kar} .7 \mathrm{gr} .}
\end{aligned}
$$

23 kar. 7 gr. $=23_{\mathrm{T}^{2}}^{\frac{7}{2} \text { kar. }}=\frac{23_{\mathrm{T}^{2}}^{\frac{7}{2}}}{24}=0,983$, zijnde het gehalte van den tegenwoordigen tijd.

Intusschen rall op te merken, dat de $w^{-t} \operatorname{van} 1847$ op het hier berekende gewicht en gehalte respectievelijt een remedie van $1 \frac{1}{2}$ vo en 0,0005 toestaat. Ook in den beeldenaar van den alouden "Nederlandtachen Ducaet met de Letteren" is een geringe wijziging aangebracht, doordien de keerzijde tegenwoordig in het vierkant de volgende letters bevat:

Mo. Aur Reg. Belgii. ad Legem Imperii.

Gouden Munt van het Koningrijk Nederland, volgens de wet van het rijk.

Bovendien beeft de Dukaat van den terrenwoordigen tijd een kartelrand. In 1749 werd reeds door de Staten-Generaal tot het iaanbrengen ran dien rand besloten om "'t schroyen der munten of 't aftrekken raet stercke wateren" te voorkomen; de na dit besluit geslagen stukken worden dan ook "gerande Dukaten" genoemd.

Is uit het bóvenstaande gebleken, dat gewicht en gebalte van den Dukaat van de rroegste tijden af tot den tegenwoordigen tijd standrastig, altinans binnen zeer enge grenzen bcperkt geweest zijn, met den prijs is het darentegen anders gesteld. Dere is, niettegenstaaude de talrijke verbodsbepalingen op "de stegge"ringe van den Gelde", waarin zelfs met verbanning, schavot en doodstraf bedreigd werd, voortdurend gestegen. Uit de voornaanste plakkaten ran de $15 \mathrm{e}, 16 \mathrm{e}$ en $17 \mathrm{e}$ eeuw geven we dienaangaande het volgende overzicht: 
Prijs van den Duknat in Guldens Plaimsche Munt, waarbij het Pond Plaamsch op zes gulden gesteld is.

\begin{tabular}{|c|c|c|c|c|c|c|c|}
\hline $\begin{array}{l}\text { JaAkTaL } \\
\text { an het Plakkaat. }\end{array}$ & & & $\begin{array}{l}\text { KoERs. } \\
\text { Guld. Stuiv. }\end{array}$ & $\begin{array}{c}\text { JAARTAL } \\
\text { van het Plikkat. }\end{array}$ & & & $\begin{array}{l}\text { KoERS. } \\
\text { Guld. Stuiv. }\end{array}$ \\
\hline 1489 & - & • & $1-6$ & 1606 & - & - & $3-16$ \\
\hline 1520 & • & • & $1-19$ & & & & $4--$ \\
\hline 1548 & - & . & $2-1$ & 1608 & 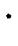 & , & - $3-18$ \\
\hline $155 \check{9}$ & - & • & $2-4$ & 1610 & & 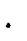 & $4--$ \\
\hline 1579 & - & • & $3-4$ & 1615 & - & - & $4-1$ \\
\hline 1581 & - & . & $3--$ & 1619 & • & • & $4-2$ \\
\hline 1586 & - & . & . $3-8$ & 1621 & & $\cdot$ & $4-4$ \\
\hline 1594 & - & • & - $\left\{\begin{array}{l}3-11 \\
3-8\end{array}\right.$ & $\begin{array}{c}1 \hat{2} 22 \\
1638-1640\end{array}$ & & & $\begin{array}{r}4-5 \\
4-10\end{array}$ \\
\hline 1596 & • & · & - $3-9$ & $1645-1655$ & & - & $4-15$ \\
\hline 1603 & - & . & $3-14$ & 1663 & & . & $5--$ \\
\hline
\end{tabular}

De koers van het jaar 1489 staat oorspronkelijk opsegeven in Tournooische Munt (zie de noot op pag. 503), en bedraa t 4 Sols, 4 deniers gros. Het Pond Tournooisch is hier gelijk gesteld an het Pond Vlaamacb. Beide hebben niet veel ran elkander kunnen verschillen, zooals blijkt uit een zinsnede van de in het genoemde jaar gegeven ordonnantio:

„A l'entree de ceste ordonnance, toutes les rentes, heritables "et viagieres, qui ont esté vendues a libures de gros monnoje "Le Flandres, se payeront en cours a libures de groz" (Tournois): "a sçaroir six Florins d'or, telz qu'ilz sont forgez par ceste "ordonuance. Et s'il advenoit que cy apres lon en voulsist aul"cune rachepter, lon payera pour cliascune liburd de gros." (Tournois) „six Florins d'or."

Het zou verder een grove dwaling zijn, uit de bovenstaande prijzen van den Dukaat te willen afleider, dat de verhouding tusschen de waarde van goud en zilver in dezelfde mate gestegen is als de koers van dit muntstuk. Tooreerst toch blijkt uit de reeds genoemde ordonnantie, dat het Poud Viaamsch gelijk gesteld werd aan 6 guliten in goud (zoogenoemde Andriesguldens), terwijl het later tegen zes gulden in zilver werd berekend; bij de telkens veranderende verhouding tusschen goud en zilver kan deze wardemeter dus niet standvastig gebleven zijn. Maar bovendien kan, zooals later blijken zal, uit de rettelijke bepalingen op het aanmunten van goud en zilver worden aangetoond, dat de verhouding tusschen de waarde dezer metalen in het jaar 1520 , b. v. voor bet goud ongrustiger was dan in 1489 , zoodat uit den hoogeren 
koers in het eersigencemde jaar alleen kan worden besloten tot een geringere waarde van het Pond Vlaamsch, onverschillig of dit in zilver of in goud moest worden berekend.

Het zal verder niet overbodig zijn op te merken, dat de hier gegeven koersen telkens door de regeering werden vàstgesteld. In $b \Leftarrow t$ verkeer stonden zij riettegenstaancie alle strafbepalingen gewoonlijk booger. En daar zij voortdurend, zooals over de jaren 1594 en 1608 uit de opgegeven prïzen bljken kan, gereduceerd werden, gaf dit dikwijls annleiding tot groote moeilijkbeden. De onlusten van het Kags-en Broodsvolk worden dan ook voornamelijk aan deze reductiën toegeschreven.

Eindelijk dient nog rermeld te worden, dat de rcgeering in 1663 er van afzag, om den koers der gouden munten vast te stellẹ. „De experientie” had, volgens harr eígen uitspraak gheleert, "dat de Goude ende Silvere Penningen seer baswaerick onder "de Goneynte, op deselve waerde van guldens, stuypers, etc. "konnen worden gehouden, mar dat deselve somwijlen, immers "voor eenigen tijdt, gevoelijck komen te steygeren", zoodat rij bepaalde, dat de prijs van goud in Dukaten zou worden opgegeven, en de booper steeds bet recht zou bebben in deze munt te betalen, wanneer de kcers daarvan, in guldens en stuivers uitgedrukt, naar zijn meening door den verkooper to hoog gestaid was. In de volgende eenw werd nog ééns van deze bepaling afgeweken, doordien in bet jaar 1760 besloten werd, dat de ontiangers der belastingen bet Mark ongerande Dukaten roor $f 365,80$ mochten aannemen, en de koers van den wichtigen dukuat derbalve op $f 5,22^{5}$ gesteld werd. En ook in deze eeur, n. 1. bij de wet van 28 September 1816 werd, maar voor 't laatst, ann dit muntstuk een vaste waarde teegekend door de bepaling, dat de Dukaat, mits gerand en wichtig, in 's Rijks kassen roor $f$,50 zou worden aangenomen.

Wanneer men den standprïg $f 1442,60$, die ten onzent bij de noteering van goud in gebruik is, vergelijht met den prijg ran het zilver, die thans p.m. $f 100$, bedraggt, dan komt men tot het vermoeder, dat dit getal afkomstig is uit den tijd, warin de verhouding van de waarde van goud en zilver ongeveer 14,5 was. $\left(^{*}\right)$ Om die verbouding in het algemeen te kunnen bereke-

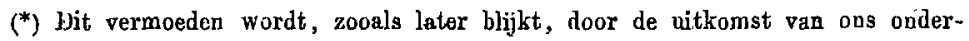
zouk bevestigd. Het hiud echter onjuist knnuen zijn, voural omdat men ì priori 
nen, moet melt bekend zijo of met de prijzen, die te gelijkertijd voor een bepaalde gewichtseenheid van beide metalen genoteerd worden, of met het gewicht, bet gehalte en de in dezelfde eenheid uitgedrukte waarde van de gouden en zilveren hoofdmunten, die te gelijkertijd ganghaar zijn. Enkele plakkaten beratten de eerstgenoemde, de meeste daarentegen de laststgenoemde gegevens. We geven dienarngaande het volgende overzicht:

Ferhouling van de waarde van Goud en Zilver, berekend naar den koers van den Dukaat en dien van een der zilveren hoofdmunten (*).

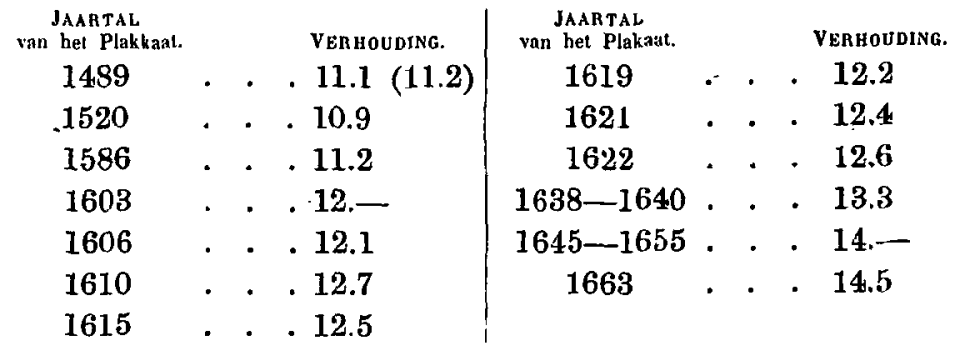

Poor de beide eerstgenoemde jaren is de rerhouding berakend vit de muntprijyen der edeje metalen.

Zoo bepaalt de ordonnantie van bet jaar 1489 , dat vonr het Trooisch Mark muntgoud „le maistre de la Monnoye donra aux "marchans et changeurs quatorse libures, quatorse sols, deux

niet weten kan, welke verandering in den gulden als waarderneter is aangebracht. Intusschen was tijdens het ontstasn van den standprijs voor goud, de prijs van het zilver inderdaad zeer nabij $f 100$.

(*) Door de welwillendheid van den redacteur kwam ons, onder de correctie van de proef, in handen: W. C. Mees. Proeve eener geschiedénis van het bankwezen in Nederlınd, gedurende den tijd der republiek. De schrijver geeft op pag. 275 en 277 van dit werk het fijn gewieht van den gnlden in goud en in zilver. Berekent men hieruit de waardeverhonding der bejde metalen, dag zijo de uitkomsten voor de jaren 1586,1606 en 1610 verschillend van de hier gegevene, hoewel die verschillen niet groot zijo $(0,1 ; 0 ; 1$ en 0 , 4.)

Dit vindt zijn verklaring in de volgende omstandigheden. De schrijver heeft remedie voor gewicht en gehalte in rekening gebracht, hetgeen hier niet geschied is, terwijl hij voor de jaren 1606 en 1610 den Rijksdaalder in plaats van den Zilveren Real tot grondslag der berekening heeft asngenomen. Door den te lagen koers van den Real in het laatsigenoemde jaar wordt het verschil van 0,4 verklaarbaar. Berekeningen, berustende op den koers van den in datzelfde jaar circlleerendén Leeuwendaalder en Tienstuiverspenning leiden intusschen ook tot de bier gegeven verhouding. Voor de volgende jaren komen de nitkomsten met elkander overeen. 
"deniers gros" (Tournooisch), terwijl het Mark muntzilver van 11 penningen, 18 grein met "vingt et cinq sols six deniers gros" betaald werd. Daar het geha!te van muntgoud niet wordt opge. geven, hebben wij dit op $23{ }_{4}^{3}$ karaat gesteld, zijnd 3 dit het hoogste gehalte, dat in dien tijd na aftrek van de remedie, gebruikt werd.

Voor het jaar 1520 is de verhouding eveneens uit de munt prijzen opgemakkt. Voor het Trooisch Mark muntgoud van 23 karaat, 9 grein werd toen betaald "XXII pont sestaion sehell. grooten Vlaems," voor het Mark fijn zilver "II pont, II scbell. groot."

Voor de jaren $1586,1603,1606$ en 1610 is de rerhouding berekend met behulp van den Dukaat en den zilveren Reaal. Daarbij is aangenomen, dat 70 Ducaten uit 1 Mark goud van 23 karaat, 8 grein en $7_{89}^{9}$ Realen uit 1 Mark zilver van 10 penningen fijn geslagen werden, zooals de plakkaten dan ook voorschreven. De koers van den Dukaat in de genoemde jaren vindt men op pag. 508 , die van den zilveren Reaal was in $1586 / 2,50$, in 1603 $f 2,55$ en in de beide laatstgenoemde jaren $f 2,60$.

Voor de volgende jaren is de koers van den Dukaat en die van den Rijksdaalder gebruikt. Van de laatstgenoemde munt gingen, volgens ket plakkaat van $1603,8 \mathrm{r}^{7} \mathrm{7}_{\mathrm{r}}^{2}$ stuklien in 1 Mark zilver van 10 penningen, 15 grcin. Zij had in 1615 een waarde van $f$ 2,40, vervolgens van $f 2,50$.

Uit de gegeven verhoudingen blijkt wel, dat de ontdekking van Amerika, die tussechen het eerste en tweede jaartal invalt, het goud heeft doen dalen, maar die daling is zoo gering, dat men tot het vermoeden komt, dat de eerstgenoemde verhouding onjuist is, betgeen alleon zou kunnen toegeschreven worden aan het door ons aangenomen gehalte van het toenmalige murtgoud $\left({ }^{*}\right)$. Zou verder de daling der goudprijzen van 1610 tot 1621 niet het ge-

$\left.{ }^{*}\right) W_{i j}$ bebben, nadat het bovenstaande reeds geschreven was, nog eeus nauwkeurig de genoemde ordonuantie van 1489 gelezen en daaruit de volgende gegeveus verzameld, die dienen kunnen ou de waarde-verhouding vau goud en zilver juist te bepalen.

De St. Andriesgulden, warran 72 geslageu werden uit een Trooisch Mark (de siz sols de taille au marq de 'Troyes) bevatte 19 karaten gond en 4 karaten zilver en werd tegen 20 stuivers (pattars) berekend. De "grand double" waarvau 39 gemunt werden uit een Mlark zilver (de 3 sols, 3 deviers de taille, all marq de Troyes) had een gehalte ran 11 penuingen, 18 grein en een waarde vau stuivers. Hieruit volyt nu:

1 Mark muntzilver van 113 penningen $=39$ "grand doubles" $=39 \times 4$ 
volg gewcest $z$ ijn ran den vredestoestand, die door bet twaalfjarig bestand in het leven geroepen werd?

We hebben, met behulp van de genoemile rerhoudingen tusachen de waarde van goud en zilver, ten prijs van den Dukaat in Ned. Cour. van den tegenwoordigen tijl bepaald, en vinden dienaangaande het volgende:

\begin{tabular}{|c|c|c|}
\hline JaARTAL. & $\begin{array}{l}\text { KOERSWAARDE. } \\
\text { tegenw. kuers }=15.75 . \\
\text { boud }=10.1 \mathrm{pCl} \\
\text { xilver }=1100 .\end{array}$ & 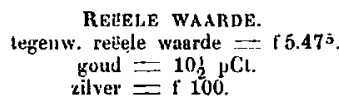 \\
\hline 1489 & $f 4 .-$ & $f 3.81$ \\
\hline 1520 & , 3.93 &, 3.74 \\
\hline 1586 & , 4.04 & , 3.85 \\
\hline 1603 & , 4.33 &, 4.12 \\
\hline 1606 & " 4.36 &, 4.15 \\
\hline 1610 & , 4.58 & , 4.36 \\
\hline 1615 & , 4.51 & $" 4.29$ \\
\hline 1619 & "4.40 & , 4.19 \\
\hline 1621 & , 4.47 & \#4.26 \\
\hline 1622 & , 454 & $n 4.33$ \\
\hline $38-1640$ & " 4.80 &, 4.57 \\
\hline $45-1655$ &, 5.05 & \#4.81 \\
\hline 1663 & " 5.23 & \# 4.92 \\
\hline
\end{tabular}

De getallen, in de tweede kolom voorkomende, geven de waarde van den Dukaat aan, berekend naar den tegenwoordigen middelkoers van $f 5.75$ en den thans bestaanden prijs van $10.1 \mathrm{pCt}$. voor goud, van $f 100$, - voor zilver, waardoor de verhouding van beide metalen gelijk wordt aan 15,94. In een volgende kolom komt de reëele waarde voor, die de Dukaat in de genoemde jaren in de thans bestaande munt had. Tegenwoordig heeft het quantum fijn goud, in deze munt aanwezig, een waarde van

stuivers $=156$ stuivers; dus 1 Mark fijn zilver (van 12 peuningen) $=15915$ stuivers.

1 Mark muntgoud bevattende 19 kar. goud en 4 kar. zilver. $=72$ Gulden dus 6 " " 44 Mark fijn goud en I Mark fijn zilver = 432 Gulden $=8640$ stuivers, en daar 1 Mark fijn zilver op $1599_{4}^{5}$ st. berekend werd, badden $4 \frac{3}{4}$ Mark fijn goud een waarde van $8480 \frac{32}{4}$ st., waaruit voor deu prijs van 1 Mark fijn goud gevondeu wordt $17853 \frac{67}{3}$ st.

Hieruit wordt nu voor de verhouding van de waarde van goud en zilver gevonden 11,2065, ten getrige dat de outdekking van goud in Amerika, dit metaal ten ontzent zeer weinig in waarde heeft doen dalen. De groote productie van zilver, die later volgde, is eeu der oorzaken, dat ua 1520 de waardeverhouding der beide inetalen zoo verbazend steeg. 
$f$ 5.4.7/ $\frac{1}{2}$. - Vergelijkt men do hier genoemde prijzen met die op pag. 508 voorkomende, dan wordt hel duidelijk, zooals daar ter plaatse opgemerkt is dat bet Pond Vlaanseh een zeer veranderlijk waardemetor geweest is. In 1489 toch was 1 gulden 6 stuivers Vlaamsch gelijk an $f 3,81$ Ned. Cour., waaruit gemakkelijk afgeleid wordt, dat het Pond Vlaansch destijds een waarde had van $f 17,58 \mathrm{rujm}$, terwijl in hel jaar 1520 die waarde reeds tot $f 11,50$ gereduceerde was. In de volgende jaren verminderde zij achtereenvolgens tot 1619 , waarna zij ongeveer standrastig bleef.

In het jaar 1663 treffen we voor het eerst de verhouding 14,5 tusschen de waarde van goud en zilver aan. In dat jaar schijnt dus de standprijs roor goud bepaald geworden te zijn. En inderdaad bevat het plakkaat van 5 October 1663 al de gegerens, die noodig zijn om wiskunstig naauwkeurig den oorsprong van dien standprijs aan te wijzen. - Het voornaamste van dit stuk laten we hier, ora het belangrijke van de zaak, volgen:

„De Staten van Hollandt ende West-Vrieslandt, Allen den"geenen die desen sullen sien ofte hooren lesen, Saluyt. Doen te nweten; Dat $\mathrm{Wij}$ in serieuse acbtinge genomen bebbende den prijs "daer op het Goudt ende Silverwerck bij de Goudt ende Silver"smeden, onder onse goede Iugesetenen ende Onderdanen, "midtsgaders oock aan anderen den voornoemden onsen Lande "frequenterende sal mogen, ende moeten gedebiteert ende verkocht "werden, ende daer over geconsidereert hebbende, of de voorsz. "prijs niet soodanich dient te werden gereguleert, dat den Kooper "waerlyck, ende effectivelyck sooveel Goudt ofte Silver, naar de "intrinsycque waerde van dien, kome te ontfangen, als bem daer "voor bij den Verkooper afgenomen werdt, ende of niet al 't "geene 't voorsz. Goudt ende Silver, den kooper tot hooger prijse "wert opgedrongen, aengesien moet werden als eene circumventie "ofte bedrogh, dewijle alle koopers van Goudt ofte Silverwerck "haer inagineren aan Goudt ofte Silver, effectivelyck te ontfan"gen de waerde, die sij daer voor in gelde betalen.

"Ende naedemael sedert vele jaren herwaerts in gebruyck is "dat de Goudt ende Silversmeden om redenen van laccasie, 't "verinteressen van hare gemaeckte wercken ende andersints, het "Goudt ende Silver van deselve baere wereken den Koopers wat "duyrder aenreeckenen, dan wel de intrinsycque waerde van dien "komt te bedragen, ende dat die van de voorsz. Neeringe in der "daet verscheyden notahle onkcsten ofte schaden bebben to sup"porteren, of (hun) derhalven oock voor 't toekomende, om alle 
"occasien ran klachten te verinijden, boven de intrinsycke waerde "van ' $t$ ' Materiael niet en dient to werden toughevoecht een rede"lycke byslach, daarmede sij kounen behouden b'ijven, ende of "in sulcken cas die van de Neeringe niet expresselick ende "strictelick soude dienen te werden gheïnjunireert de voorsz. "byslach den Kooper (om bem voor alle misleydinge ende bedroch "te berryden) niet op de masea van het Goudt ofte Silver ende "sulctss als een ghedeelte ran de waerde van dien, man in een "post apart aen te rekenen ende afte vorderen.

„Ende daer en boven aengemerckl, dat de Goude ende Silvere "Penningen somwijlen gevoelyek tomen te steygeren, ende dat "daerdoor den prijs van 't Goud ende Silver, als die in guldeus "stuyvers etc. gedetermineert wert, ooek nootsaeckelyck moet "komen te veranderen, of niet derbaliven, ende omme hetselve "inconvenient te vermijden, de prijs ran 't voorsz. Goudt ende "Silver, behoort te werden ghesteit, niet op dus, of sooveel "guldens, stuyvers, etc. maer op dus, of sooveel stucken van "een bekendo ganckbare Nederiandtsche Goude ende Silvero "Penninch reapective, als bij exempel, voor 't Marck Goudts, "dus of soo veel Ducaten, sonder aenschouw te nemen, of de „Ducaet op vier gulden vyfthien stuyvers, op rijf gulden of oock "op minder ofte meerder quantiteyt van guldens ende stuyंvers "mochte cours hebben; Gelyck de prije van 't Goudt ende Silver, "om de selve reden van allen ouden tyde bij de Placaten op de "Munte, ende bij de Instructien voor de Munt-messteren-altijdte " in dier voegen gereguleert is geweest.

„Ende eijndelijck of niet den Goudt ende Silversmeden als voor "desen, sco oock roor 't toekromende, vrij soude behooren to "werden ghelaten om den koopers over 't fatçoen van hare wercken "soo veel af te nemen, als sij van deselve sullen kunnen bedin"ger. Soo ist, dat wij in allen dien willende voorsien, ten bester "soo wel van de voorseyde Goudt ende Silversmeden, als van "alle andere onse goede Ingesetenen endo Onderdanen, naer rijpe "deliberatie goetghevonden, geordonneert ende gestatueerd hebben, "vinden goet, ordonneren ende statueren mits desen, dat, ach"tervolgende exacte gedaene bereeckeninge, bet materiael van "'t Goudt ende Silver, bij de Goudt ende Silversmedeu, niet "hooger sal mogen werden verkocht als volght, te weten:

$$
\text { „Van 't fijn Goudt, }
$$

"tot drie en twintich caraten ende acht grain 
stucken Jucaten

"Het Marek tot . . . . . 70 $\frac{1}{72}$

„Dat is als den Ducaet coura heeft

"tegen vijf gulden

gul. stuyv. peu.

"Het Marck tot . . . . . 350. 1. 6." enz.

"Ordonnerende, dat de prijs van 't Goudt sal moeten werden "uit,redruckt bij Ducaten, ende ghedeelten van een Ducaet."

"Ordonnerende daer beneffens, dat de Goudt enle Silversmeden "haere reeckeningen aliijts sullen hebben te stellen op yeder stuck "wereks in drie posten; de eerste houdende den prijs, ofte "d'intrinsyeque waerde van 't Goudt ofte Silver, hiernaar gheëx"presseert; de tweede 't beloop van de roor geroerde bijslach" (ook bij het plakkaat bepaald), ,ende de derde 't geen over't fatçoen "betaelt moet wer?en; ende dat, ten aensien van 't Goudt in "Ducaten, ende ghedeelten ran deselre, met begrooting ran de "geheele somme in Ducaten, ende alsdan daer onder stellende, "hoeveel de gebesle somme beloopt in guldens, stuyvers ende "penningen, naer den cours van den Ducaet alsdan wesende," enz.

Bij dit plakkaat werd dus de eerste schrede gedaan op den weg, die tot den vrijen bandel in edele metalen geleidde. Was men ook al verplicht het Mark goud voor een bepaald aantal Dukaten in rekening te brengen, de goud-en zilversmeden konden hun winst zoeken, voor een gedeelte in den vastgestelden "bijslagh," voor de rest in het "fatçoen" hunner werken, en de waardeverhouding der edele metalen zou overigens geheel beheerscht worden door de wet ran vraag en aanbod. Geen wonder dan ook, dat de bandel de uit dit plakkaat voortvloeiende waarde als norm der goudprijzen aannam. Daar het gebalte van het destijds gebruikelijke "fijn goult" (ducatengoud) 23 karaten, 8 grein bedroeg, en de Dukaat tegen $f 5$.- berekend werd, verkreeg men den bedoelden standprijs als volgt:

$$
\begin{gathered}
23 \frac{2}{3}: 24=70 \frac{1}{12}: x \\
x=71 \quad \text { Dukaten (nauwkeurig) } \\
\text { of } f 355, \text { - voor } 1 \text { Mark fijn goud. }
\end{gathered}
$$

Vraagt men naar de reden, waarom veor het Marí goud $70 \frac{1}{12}$ Dukaten betaald moesten worden, terwijl 70 Dukaten een Mark moesten wegen, dan geven de plakkaten daarop geen direct antwoord. Intusschen kan zij, onzes inziens, alleen gelegen zijn in de afwijkingen vnor gewicht en gehalte, die de wet toestond.

ECoN 1875 . 
De remedie voor het gebalte van goud van de hoogste keur was gelijk aan die van den Dukaat en kan dus buiten beschouwing blïven. Die voor het gewicht was bij Dukaten een Engels per Mark, bij verwerkt goud een "troyken" (drie azen). Neemt men deze gegevens in de berekening op, dan vindt men, dat een Mark fijn goud bij het verwerken op ruim 71 Dukaten kwam te staan.

Hoe bet zij, de standprijs van 71 Dukaten of $f 355$ per Mark fijn, werd voortaan bij de noteering ran goud algemeen gebruikt on bleef tot de invoering van het metriek stelsel van maten on gewichten in ons land bestaan, maar bij de telkens veranderende verhouding tusschen de waarde van goud en zilver, werd al spoedig op het goud een agio bedongen, dat in percenten van de vaste waarde genoteerd werd.

Zoo stonden in 1792 op „de prijglijsten van specien" baren goud "7 $7 \frac{1}{2}$ p.Cto Cassa tegens $f 355$ 't mark fijn", terwijl in de laatsto maanden van 1804 die prijs tot $12 \frac{3}{4} \mathrm{pCt}$. steeg. Toen nu, bij de wet van 21 Augustus 1816, het gebruik van de nieuwe maten en gewichten na 1 Januari 1821 verplichtend werd, bleef men rasthouden aan de noteering in percenten, en werd dientengevolge de vaste waarde veranderd in dezelfde verhouding, waarin het Mark Trooisch en het Kilogram tot elkander staan, zooals blijkt uit de volgende evenredigheid:

$$
\begin{gathered}
\begin{array}{c}
\text { Mark Tr. } \\
1
\end{array}: \begin{array}{l}
\text { K. G. } \\
\text { Gram }
\end{array} \text { Gram }=f 355 .-: f x \\
\text { of } \frac{246,084: 1000=f 355 .-: f x}{x=f 1442,60 .}
\end{gathered}
$$

Uit het bovenstaande blijkt dus, dat de tegenwoordige standprijs voor goud in het jaar 1663 door den handel werd vastgesteld, als gevolg van bet in dat jaar gegeven plaksaat omtrent do prijzen van goud en uilver, en dat daarbij de koers van den Dukaat als grondelag van de berekening werd aangenomen. Hij dankte zijn ontstaan, blijkens het genoemde plakkaat, aan de "experientie”, die geleerd had, "dat do Goude en Silvere „Penningen seer "beswaerlick op deselve waerde van Guldens etc. konnen worden "gehouden", en hij staat dus met zijn historisch-antiquarische waarde dáár, als getuige ran het banvonnis, dat reeds in het midden der zeventiende eeuw, tegen den dubbelen standarard werd uitgesproken.

Amsterdam, Mei 1875.

C. KNAPPER Kz. 